REALA, número 13, abril-septiembre de 2020

Sección: ESTUDIOS BREVES

Recibido: 08-01-2020

Modificado: 03-03-2020

Aceptado: 04-03-2020

DOI: $10.24965 /$ reala.i13.10760

Páginas: 93-109

\title{
Excedencia voluntaria por interés particular en la función pública local: el reingreso al servicio activo
}

\section{Voluntary leave on personal grounds in the local civil service: return to active duty}

\author{
Mauricio Ruiz Ceniceros \\ Universidad de Vigo (España) \\ ORCID: https://orcid.org/0000-0002-6142-2587 \\ maruiz@uvigo.es
}

\section{NOTA BIOGRÁFICA}

Licenciado en Derecho por la Universidad de Santiago de Compostela (1993). Doctor en Derecho por la Universidad de Vigo (2017). Abogado en ejercicio (desde 1993). Profesor asociado de la Universidad de Vigo (desde 2015). Sus líneas de ejercicio profesional e investigación se centran en urbanismo y ordenación del territorio, contratación pública, subvenciones, empleo público y jurisdicción contenciosoadministrativa.

\section{RESUMEN}

El objeto del presente artículo es resolver las dudas que genera en la función pública local el reparto constitucional de competencias regulatorias, la sucesiva superposición de reformas legislativas y la pervivencia de leyes y reglamentos obsoletos, en cuanto al plazo máximo de duración de la excedencia voluntaria por interés particular y las condiciones de reingreso al servicio activo.

\section{PALABRAS CLAVE}

Excedencia; funcionario público; reingreso; servicio activo; situación administrativa.

\begin{abstract}
The purpose of this article is to solve the doubts arisen from the constitutional distribution of powers to rule the local civil service, from the successive overlapping of legislative amendments and from the persistence of obsolete laws and regulations, as regards to the maximum duration of leaves on personal grounds and the conditions of return to active duty.
\end{abstract}

\section{KEYWORDS}

Leave; civil servant; return; active duty; administrative situation.

\section{SUMARIO}

INTRODUCCIÓN. 1. DURACIÓN DE LA EXCEDENCIA VOLUNTARIA POR INTERÉS PARTICULAR EN LA FUNCIÓN PÚBLICAAL SERVICIO DE LAADMINISTRACIÓN LOCAL. 1.1. DISTRIBUCIÓN DE COMPETENCIAS REGULATORIAS. 1.2. DURACIÓN DE LA EXCECEDENCIA VOLUNTARIA POR INTERÉS PARTICULAR DE FUNCIONARIOS DE LAADMINISTRACIÓN LOCAL CON HABILITACIÓN DE CARÁCTER NACIONAL. 1.3. COMUNIDADES AUTÓNOMAS QUE NO REGULAN LA DURACIÓN MÁXIMA DE 
REALA. Nueva Época - N. ${ }^{13}$, abril-septiembre 2020 - ISSN: 1989-8975 - DOI: 10.24965/reala.i13.10760 - [Págs. 93-109]

Excedencia voluntaria por interés particular en la función pública local: el reingreso al servicio activo

Mauricio Ruiz Ceniceros

\begin{abstract}
LA EXCEDENCIA VOLUNTARIA POR INTERÉS PARTICULAR DE LOS FUNCIONARIOS DE LA ADMINISTRACIÓN LOCAL. 1.4. COMUNIDADES AUTÓNOMAS QUE REGULAN EL PLAZO MÁXIMO DE DURACIÓN DE LA EXCEDENCIA VOLUNTARIA DE LOS FUNCIONARIOS DE LA ADMINISTRACIÓN

LOCAL. 1.4.1. Comunidades autónomas que establecen un plazo máximo de duración con rango legal.

1.4.2. Comunidades autónomas que establecen un plazo máximo de duración con rango reglamentario. 2. REINGRESO AL SERVICIO ACTIVO. 2.1. CONCURSO O LIBRE DESIGNACIÓN. 2.2. ADSCRIPCIÓN PROVISIONAL. 2.3. AMORTIZACIÓN DE PLAZA VACANTE. CONCLUSIONES FINALES. BIBLIOGRAFÍA. ANEXO JURISPRUDENCIA. ANEXO NORMATIVO.
\end{abstract}

\title{
INTRODUCCIÓN
}

Nuestro ordenamiento parte de la base de que la situación normal en la función pública es el servicio activo y lo excepcional todas las demás situaciones que, además, deben estar explícitamente previstas en la normativa y cuyos efectos son exclusivamente los allí reconocidos (Martínez de Pisón, 1995: 317). Esto es así hasta el punto de que se entiende por situaciones administrativas distintas a las del servicio activo todas aquellas en las que los funcionarios y funcionarias, sin perder la condición de tal y manteniendo una relación de servicio con la Administración, pueden temporalmente dejar de prestar un servicio activo en los puestos de la plantilla que les correspondan según el cuerpo al que pertenezcan ${ }^{1}$. De este modo la relación de servicio no se extingue y el sujeto conserva «latente» la condición de funcionario de una Administración a la que, de forma más o menos coyuntural, ha dejado de prestar servicios (Gamero y Fernández, 2018: 365).

Lo llamativo es que, a pesar de la hiperregulación normativa que caracteriza el régimen jurídico de la función pública en general y sus situaciones administrativas en particular ${ }^{2}$, ningún texto normativo define cada uno de sus diferentes tipos (Manzana, 1998: 7). Su comprensión conceptual se remite a la mera comparación entre la situación de mayor plenitud, que es la denominada situación administrativa de servicio activo, y la de menor contenido, que es la pérdida de condición de funcionario. Todos los restantes estados entre esos dos extremos en que se encuentre la persona funcionaria determina la comprensión y contenido de cada una de las modalidades de situaciones administrativas, incluyendo la eventual reincorporación al servicio activo (Morillo-Velarde, 1985: 525) .

Por otro lado, toda situación administrativa que no sea de servicio activo supone una suspensión o una modificación de la relación de servicio en la que resulta determinante la posible reversión de sus efectos ${ }^{4}$. Es decir, la posibilidad de regresar, en la medida de lo permitido, a la situación de origen si cumplen condiciones establecidas en función de la situación administrativa de que se trate. Por ejemplo, tradicionalmente el legislador ha favorecido a aquellas actividades relacionadas con el ejercicio de cargos públicos en sentido estricto, posibilitando o favoreciendo el acceso de los funcionarios a tales cargos o funciones incompatibles con el servicio activo; y recientemente ha incorporado actividades relacionadas con la vida familiar (cuidado de hijos y otros parientes), hasta entonces englobadas como simples actividades de carácter privado (Gamero y Fernández, 2018: 305 y 306). Es decir, el régimen de reincorporación es un aspecto fundamental para la efectividad de estas situaciones administrativas porque los interesados se acogen a ellas en función, entre otros aspectos, de cuando y como podrán reingresar al servicio activo (Parada y Fuentetaja, 2015: 334)

1 Así lo entiende DE LA VALLINA (1962: 463), aunque tampoco excluye la situación administrativa primigenia que es, precisamente, la situación en servicio activo regulada en los arts. 85.1.a) y 86 del Real Decreto Legislativo 5/2015, de 30 de octubre, por el que se aprueba el texto refundido de la Ley del Estatuto Básico del Empleado Público.

2 Así califica el actual régimen regulatorio LORENZO (2005: 314).

3 Aunque es una conceptualización en bucle porque, a su vez, el art. 86.1 del Real Decreto Legislativo 5/2015, de 30 de octubre, por el que se aprueba el texto refundido de la Ley del Estatuto Básico del Empleado Público establece que: «Se hallarán en situación de servicio activo quienes, conforme a la normativa de función pública dictada en desarrollo del presente Estatuto, presten servicios en su condición de funcionarios públicos cualquiera que sea la Administración u organismo público o entidad en el que se encuentren destinados y no les corresponda quedar en otra situación».

4 En concreto, GARCÍA-TREVIJANO (1954: 69 y 70) entiende que la situación de excedencia voluntaria supone que extinción de la relación orgánica y la paralización de la de servicio. Sin embargo, para LORENZO (2005: 314): «La naturaleza jurídica de las situaciones administrativas constituye una suspensión de la relación orgánica del funcionario con la Administración, o, más concretamente, como una modificación del contenido de la relación jurídica que une al funcionario con la Administración». Fundamenta su opinión en la de PRAGA, I. (1961): Il personále nella publica Administratione, pág. 113, BOLONIA Y SANDULL, M. (1957): Manuale di diritto administrativo, págs. 153 y ss. Nápoles.

5 Porque uno de los elementos esenciales de las situaciones administrativas es «[...] las consecuencias jurídicas ligadas a su terminación» (STC 1/2003, Pleno, de 16 de enero de 2003, Rec. 2987/1995, FJ 8). 
En realidad, en toda la normativa reguladora de las diferentes situaciones administrativas que no son servicio activo se atisba un interés público más o menos concreto, pero siempre latente, en no perder efectivos ya incorporados a la función pública (Fuentetaja y Gil, 2018: 21). Después de haber invertido tiempo y medios en formar a un empleado público, la Administración procura optimizar sus recursos conservándolo en plantilla o, en el peor de los casos, manteniendo factible su reincorporación. Sin embargo, este criterio también es cuestionable porque, desde el punto de vista de la eficiencia, la situación administrativa de excedencia perturba el buen funcionamiento de la Administración y del servicio público desde el momento en que constituye una excepción a la normal prestación de servicios profesionales. Si además dicha situación se prolonga excesivamente en el tiempo, parece inoperativo tener una estructura organizativa en permanente provisionalidad para, finalmente, recuperar a un empleado cuya formación y conocimientos pueden estar obsoletos. A pesar de lo cual históricamente el objetivo de conservar al funcionario público es el que más peso ha tenido en el régimen jurídico de la excedencia voluntaria por interés particular.

Partiendo de estas premisas, el objeto del presente artículo es resolver las dudas a la que se enfrenta cualquier funcionario o funcionaria de la Administración local que pretenda solicitar su excedencia voluntaria por interés particular: ¿podrá reingresar, cuándo y cómo? Preguntas sin respuesta sencilla como consecuencia de los avatares legales que ha padecido esta materia.

\section{DURACIÓN DE LA EXCEDENCIA VOLUNTARIA POR INTERÉS PARTICULAR EN LA FUNCIÓN PÚBLICA AL SERVICIO DE LA ADMINISTRACIÓN LOCAL}

En el acervo común la excedencia voluntaria por mero interés particular es la «excedencia» por antonomasia, porque permite a los funcionarios públicos separarse del servicio activo por razones estrictamente personales y profesionales con mínimas restricciones, durante un período temporal mínimo y con determinadas condiciones de reingreso ${ }^{6}$. Aunque la denominación "voluntaria» induce a equívoco, porque esta situación administrativa puede no ser querida ni promovida por el funcionario o funcionaria afectado ${ }^{7}$, en cuyo caso la excedencia voluntaria de interés particular será declarada de oficio ${ }^{8}$, sin perjuicio de que los plazos de duración y los requisitos de reingreso sean los mismos. Lo que varía es el punto de partida: voluntaria a instancia de parte y «voluntaria» de oficio.

En todo caso, uno de los aspectos más importantes de este tipo de excedencia es su duración, es decir el período mínimo de permanencia y el tiempo máximo de mantenimiento sin perder la condición de funcionario o funcionaria ${ }^{9}$.

6 Porque «La motivación de la solicitud de excedencia voluntaria por interés particular pertenece al ámbito subjetivo del funcionario» (STSJ de Cataluña, Sala de lo Contencioso-administrativo, Sección 4. ${ }^{\text {, }}$, de 20 de junio de 2019, Rec. 330/2017, FJ 5), frente a los otros tipos de excedencias, como por ejemplo las excedencias por agrupación familiar, por cuidado de familiares y por razón de violencia de género. Los únicos requisitos previos son el período mínimo de servicio activo, que las necesidades del servicio lo permitan y que no se le esté instruyendo expediente disciplinario (art. 89.2 del Real Decreto Legislativo 5/2015, de 30 de octubre, por el que se aprueba el texto refundido de la Ley del Estatuto Básico del Empleado Público). Para contrastar la singularidad de esta excedencia, véase PARADA y FUENTETAJA (2015: 319) y FUENTETAJA y GIL (2018: 80).

7 Por ejemplo, para la persona funcionaria en suspensión de funciones que haya omitido la obligación de presentar el reingreso al servicio activo en el plazo fijado (art. 22.4 del Real Decreto 365/1995, de 10 de marzo, por el que se aprueba el Reglamento de situaciones administrativas de los funcionarios civiles de la Administración General del Estado); o cuando se articula como situación administrativa residual para aquellos funcionarios públicos que presten servicios en organismos o entidades que queden excluidos de la consideración de sector público a estos efectos (art. 29.3. ${ }^{\circ}$.c) de la Ley 30/1984, de 2 de agosto, de Medidas para la reforma de la Función Pública); o cuando el funcionario en situación administrativa de servicio en otra Administración pública cese en su puesto de libre designación, la Administración de destino no le adscriba a otro puesto, y en el plazo máximo de un mes no solicite el reingreso al servicio activo en su Administración de origen; o cuando finalizada la causa que determinó el pase a una situación distinta a la de servicio activo, se incumpla la obligación de pedir el reingreso (arts. 84.3 y 89.2 del Real Decreto Legislativo 5/2015, de 30 de octubre, por el que se aprueba el texto refundido de la Ley del Estatuto Básico del Empleado Público); o cuando los funcionarios de la Administración local con habilitación de carácter nacional no tomen posesión de los puestos de trabajo obtenidos en el concurso en los plazos establecidos (art. 42.4 del Real Decreto 128/2018, de 16 de marzo, por el que se regula el régimen jurídico de los funcionarios de Administración Local con habilitación de carácter nacional).

8 La STS, Sala Tercera, de lo Contencioso-administrativo, Sección 7. a , de 20 de mayo de 1993, FJ 2, cuestiona lege ferenda «[...] el acerito técnico del legislador al calificar de voluntaria una situación, en la que no existe solicitud del interesado para acceder a ella». Pero lo cierto es que se puede identificar una actuación tácita en tal sentido cuando el funcionario se mantiene pasivo y no solicita el reingreso al servicio activo (FUENTETAJA y GIL, 2018: 82).

9 En cuanto al alcance de esta relevancia, véase FUENTETAJA y GIL (2018: 82). 


\subsection{Distribución de compentencias regulatorias}

El régimen jurídico de la excedencia voluntaria está inevitablemente condicionado por el reparto competencial que en esta materia ha trazado el art. 149.1.18. ${ }^{a}$ de la Constitución, en virtud del cual corresponde al Estado la competencia exclusiva para la fijación de las bases en materia de situaciones administrativas ${ }^{10}$. Bases que el Estatuto Básico del Empleado Público ha reducido al mínimo, reservándose únicamente la regulación de las situaciones administrativas que considera claves para definir el marco común (Fuentetaja, 2013: 501), hasta el punto de que las situaciones administrativas en las que se puede encontrar una persona funcionaria no tienen por qué ser las mismas en todas las administraciones públicas españolas, siempre que se respeten las comunes (servicio activo, servicios especiales, servicio en otras administraciones públicas, excedencia y suspensión de funciones) ${ }^{11}$. Además, el Estatuto Básico del Empleado Público remite a la potestad reglamentaria de las comunidades autónomas la fijación de los plazos, procedimientos y condiciones para ejercer el derecho al reingreso, en los casos en que proceda conforme al propio Estatuto ${ }^{12}$.

En lo que atañe a las situaciones en que pueden hallarse los funcionarios de carrera de la Administración local, se rigen por la normativa básica estatal y por la legislación de función pública de la respectiva comunidad autónoma y, supletoriamente, por la legislación de los funcionarios de la Administración del Estado, sin perjuicio de las peculiaridades del régimen local ${ }^{13}$. Por tanto, el dato clave para determinar el régimen aplicable es saber si ley autonómica ha incluido o no dentro de su ámbito de aplicación a las corporaciones locales, porque si no es así se les habrá de aplicar la legislación estatal y sus disposiciones de desarrollo. Además, todavía puede quedar margen para que la propia Administración local reglamente peculiaridades de sus funcionarios, siempre que sea acorde con la legislación básica del Estado, con las leyes que las comunidades autónomas hayan dictado para los funcionarios de las entidades locales en sus ámbitos territoriales y con las dictadas por el legislador estatal para sus propios funcionarios de la Administración General del Estado ${ }^{14}$.

Por último, como consecuencia de la reserva de ley consagrada en el art. 103.3 de la Constitución, las disposiciones reglamentarias dictadas por la Administración Autonómica en esta materia tienen únicamente carácter supletorio respecto de los reglamentos que dicten las propias administraciones locales. Es decir, en virtud de la potestad de autorregulación local para desarrollar disposiciones legales, los reglamentos autonómicos sólo entrarán en juego en defecto de reglamentación local propia (Fuentetaja, 2010: 353).

En materia de duración de la excedencia voluntaria por interés particular, el resultado de esta distribución competencial es el siguiente: en primer lugar, el Estatuto Básico del Empleado Público no impone un tiempo mínimo de duración de la excedencia voluntaria por interés particular, sino que lo remite a las leyes de función pública que se dicten en su desarrollo, o a las normas vigentes mientras no haya otro desarrollo legislativo ${ }^{15}$; en segundo lugar, el Estatuto guarda un absoluto silencio sobre los períodos de permanencia máxima y tampoco lo remite a un posterior desarrollo normativo. Laguna que, por el momento, suplen otras leyes y reglamentos obsoletos y descoordinados.

10 STC 1/2003, Pleno, de 16 de enero de 2003, Rec. 2987/1995, FJ 5, porque: «Las situaciones administrativas que pueden acontecer a lo largo de la carrera funcionarial constituyen un aspecto fundamental del estatuto de los funcionarios públicos (STC 99/1987, de 11 jun., FJ 3 c), y 37/2002, de 14 Feb., FJ 5)».

11 Art. 85.2 del Real Decreto Legislativo 5/2015, de 30 de octubre, por el que se aprueba el texto refundido de la Ley del Estatuto Básico del Empleado Público.

12 Art. 91 del Real Decreto Legislativo 5/2015, de 30 de octubre, por el que se aprueba el texto refundido de la Ley del Estatuto Básico del Empleado Público y PARADA y FUENTETAJA (2015: 303 y 327).

13 Art. 140.2 del Real Decreto Legislativo 781/1986, de 18 de abril, por el que se aprueba el texto refundido de las disposiciones legales vigentes en materia de régimen local, en relación con el art. 3 del Real Decreto Legislativo 5/2015, de 30 de octubre, por el que se aprueba el texto refundido de la Ley del Estatuto Básico del Empleado Público, y el art. 92.1 de la Ley 7/1985, de 2 de abril, reguladora de las Bases del Régimen Local.

14 Con el margen que señalan FUENTETAJA y GIL: «[...] una Administración local no podrá crear situaciones nuevas, pero sí reordenar a las existentes legalmente (básicas y de desarrollo) situaciones propias o específicas de su ámbito organizativo, originadas desde formas de provisión adicionales a las también básicas o bien desde el ámbito de las licencias y permisos de sus funcionarios» (2018: 40 y 41).

15 Art. 89.2 del Real Decreto Legislativo 5/2015, de 30 de octubre, por el que se aprueba el texto refundido de la Ley del Estatuto Básico del Empleado Público y SJCA núm. 3 de Pontevedra, de 19 de septiembre de 2016, P. A núm. 135/2016, FJ 2. 
REALA. Nueva Época - N. ${ }^{13}$, abril-septiembre 2020 - ISSN: 1989-8975 - DOI: 10.24965/reala.i13.10760 - [Págs. 93-109]

Excedencia voluntaria por interés particular en la función pública local: el reingreso al servicio activo

Mauricio Ruiz Ceniceros

\subsection{Duración de la excecedencia voluntaria por interés particular de funcionarios de la Administración local con habilitación de carácter nacional}

En la Administración General del Estado el funcionario o funcionaria en excedencia por interés particular no puede permanecer en ella menos de dos años continuados ${ }^{16}$, que es el mismo plazo durante el cual los funcionarios de la Administración local con habilitación de carácter nacional no pueden concursar a los puestos de trabajo ${ }^{17}$. En cuanto a la duración máxima, en las resoluciones por las que se declare esta situación se expresará el plazo máximo de duración de la misma, que en todo caso no debe superar el número de años equivalente a los que el funcionario o funcionaria acredite haber prestado en cualquiera de las administraciones, con un máximo de quince (art. 16.3 y 4 del Real Decreto 365/1995, de 10 de marzo, por el que se aprueba el Reglamento de situaciones administrativas de los funcionarios civiles de la Administración General del Estado $)^{18}$. Pero esta norma reglamentaria, redactada conforme a la legislación entonces vigente, fue tácitamente derogada por la Ley 13/1996, 30 diciembre, de Medidas Fiscales, Administrativas y del Orden Social, que eliminó en el art. 29.3.c) de la Ley 30/1984 cualquier referencia a un límite temporal. Es decir, cabe entender que tal condición ya no es exigible. Todo ello con una técnica legislativa manifiestamente mejorable, porque una materia como esta exige una disposición derogatoria expresa ${ }^{19}$.

En todo caso, cabe afirmar que el régimen aplicable a los funcionarios de la Administración local con habilitación de carácter nacional en excedencia voluntaria por interés particular es el siguiente: deben permanecer en dicha situación como mínimo dos años continuados; pero su reingreso no está sujeto a plazo alguno, pudiendo solicitarlo cuando convenga a sus intereses particulares ${ }^{20}$.

\subsection{Comunidades Autónomas que no regulan la duración máxima de la excedencia voluntaria por interés particular de los funcionarios de la Administración local}

En este grupo se pueden distinguir dos tipos de legislaciones autonómicas. Por una parte, las que únicamente regulan las situaciones administrativas de los empleados públicos autonómicos y dejan fuera de su ámbito de aplicación al personal de la Administración local (Andalucía y la Región de Murcia) ${ }^{21}$. También se puede incluir a la legislación aragonesa, que no regula las situaciones administrativas de nadie ${ }^{22}$. Por lo que en estas comunidades autónomas se aplica con carácter supletorio la normativa de la Administración General del Estado, es decir, deben mantenerse en esta situación un tiempo mínimo de dos años continuados.

16 Art. 29.3.c) de la Ley 30/1984, de 2 de agosto, de Medidas para la reforma de la Función Pública y art. 16.2 del Real Decreto 365/1995, de 10 de marzo, por el que se aprueba el Reglamento de situaciones administrativas de los funcionarios civiles de la Administración General del Estado.

17 Art. 36.2.c) del Real Decreto 128/2018, de 16 de marzo, por el que se regula el régimen jurídico de los funcionarios de Administración local con habilitación de carácter nacional.

18 La versión originaria del art. 29.3.c) de la Ley 30/1984, de 2 de agosto, de Medidas de reforma de la Función Pública establecía que no se podía permanecer en ella más de diez años continuados. Pero la Ley 22/1993, de 29 de diciembre, de medidas fiscales, de reforma del régimen jurídico de la función pública y de la protección por desempleo modificó este apdo. $3 . c)$ y lo amplió a 15 años.

19 Originariamente el art. 129.3 de la Ley de Procedimiento Administrativo de 17 de julio de 1958 obligaba a que todo proyecto de nueva disposición fuese acompañado por una tabla de vigencias de disposiciones anteriores sobre la materia y consignase expresamente las anteriores que debían quedar total o parcialmente derogadas. Hasta que la Ley 50/1997, de 27 de noviembre, del Gobierno eliminó esta obligación. Ha habido sucesivos intentos para recuperar aquella buena técnica normativa, como por ejemplo el apdo. 41 de las Directrices de Técnica Normativa, aprobadas por Acuerdo del Consejo de Ministros de 22 de julio de 2005 ; el Real Decreto 1083/2009, de 3 de julio, Memoria del análisis de impacto normativo y la disposición final tercera de la Ley 40/2015, de 1 de octubre, de Régimen Jurídico del Sector Público, que modifica el art. 26.3.b) de la Ley 50/1997, y en el ámbito autonómico el art. 41.2. de la Ley 16/2010, de 17 de diciembre, organización y funcionamiento Administración general y sector público autonómico de Galicia. Todos ellos prescriben la obligación de incluir el listado pormenorizado de las normas derogadas como consecuencia de la entrada en vigor de las nuevas normas legales y reglamentarias. Pero con escaso éxito, porque las disposiciones derogatorias continúan conteniendo meras cláusulas genéricas de derogación del derecho vigente, sin indicar las normas o partes de ellas que se derogan y las que se mantienen en vigor. De este modo perviven en el ordenamiento jurídico diversas normas contradictorias con el mismo ámbito de aplicación.

20 En este sentido véase LORENZO (2004: 338) y FUENTETAJA y GIL (2018: 82), así como el art. 36.2.c) del Real Decreto $128 / 2018$, de 16 de marzo, por el que se regula el régimen jurídico de los funcionarios de Administración local con habilitación de carácter nacional.

21 Arts. 1, 2 y 3 de la Ley 6/1985, de 28 de noviembre, de Ordenación de la Función Pública de la Junta de Andalucía, y art. 1 del Decreto Legislativo 1/1991, de 19 de febrero, por el que se aprueba el Texto Refundido de la Ley de Ordenación de la Función Pública de la Comunidad Autónoma de Aragón.

22 Art. 1 del Decreto Legislativo 1/1991, de 19 de febrero, por el que se aprueba el Texto Refundido de la Ley de Ordenación de la Función Pública de la Comunidad Autónoma de Aragón. 
Pero no tienen plazo máximo de duración, pudiendo solicitar el reingreso en cualquier momento posterior a dicho plazo mínimo.

El segundo subgrupo son las leyes de función pública de las Castilla y León, Castilla-La Mancha, Comunidad Valenciana, Comunidad de Madrid, Extremadura, Islas Baleares, País Vasco y Comunidad Foral de Navarra, que se aplican al personal al servicio de la Administración de la comunidad autónoma y al personal de la Administración local y foral ${ }^{23}$. Estas comunidades autónomas han adaptado su legislación al régimen básico estatal, porque establecen que la excedencia voluntaria por interés particular debe durar de manera continuada como mínimo dos años (Castilla y León, Comunidad Valenciana, Comunidad de Madrid, Extremadura y el País Vasco) o un año (Castilla-La Mancha) o incluso ninguno (Islas Baleares) ${ }^{24}$. Pero no imponen un plazo máximo de duración, acorde con la normativa estatal vigente desde el 1 de enero de $1997^{25}$. Por lo que cabe entender que en los funcionarios de las entidades locales con sede en estos territorios pueden permanecer en situación de excedencia voluntaria indefinidamente, sin perder por ello el derecho al reingreso.

La legislación que no deja margen de duda es la navarra, porque no establece ningún plazo mínimo de permanencia y dispone expresamente que «[...] se entenderá concedida, en todo caso, por tiempo indefinido». Incluso la persona funcionaria goza de reserva de plaza de origen durante los primeros 18 meses de excedencia ${ }^{26}$.

\subsection{Comunidades autónomas que regulan el plazo máximo de duración de la excedencia voluntaria de los funcionarios de la Administración local}

La interpretación es mucho más confusa en aquellas comunidades autónomas donde el personal al servicio de las administraciones locales está sujeto a las respectivas leyes de función pública autonómicas (Islas Canarias, Cantabria, Cataluña, Galicia, La Rioja y Principado de Asturias), pero no han adaptado su normativa a los nuevos criterios de la legislación básica estatal ${ }^{27}$. Ordenamientos autonómicos en los que, a su vez, cabe distinguir dos tipos de complejidades en función de si el plazo máximo está regulado por una disposición legal o por una norma reglamentaria.

\subsubsection{Comunidades autónomas que establecen un plazo máximo de duración con rango legal}

Por un lado, están las comunidades autónomas cuyas leyes de función pública establecen un tiempo mínimo de permanencia (dos años en La Rioja y Principado de Asturias, y un año en Cantabria y las Islas

23 Art. 2.1 y 6 de la Ley 7/2005, de 24 de mayo, de la Función Pública de Castilla y León; art. 2.1 de la Ley 4/2011, de 10 de marzo, del Empleo Público de Castilla-La Mancha; art. 3.1 de la Ley 10/2010, de 9 de julio, de la Generalitat, de Ordenación y Gestión de la Función Pública Valenciana; art. 1 de la Ley 1/1986, de 10 de abril, de la Función Pública de la Comunidad de Madrid; art. 3.1 de la Ley 13/2015, de 8 de abril, de Función Pública de Extremadura; art. 3 de la Ley 3/2007, de 27 de marzo, de la Función Pública de la comunidad autónoma de las Islas Baleares; art. 2.1 de la Ley 6/1989, de 6 de julio, de la Función Pública Vasca, y art. 1 del Decreto Foral Legislativo 251/1993, de 30 de agosto, del Texto Refundido del Estatuto del Personal al Servicio de las Administraciones Públicas de Navarra.

24 Art. 91.2 de la Ley 7/2005, de 24 de mayo, de la Función Pública de Castilla y León; art. 127.1 de la Ley 10/2010, de 9 de julio, de la Generalitat, de Ordenación y Gestión de la Función Pública Valenciana; art. 59.2.b) de la Ley 1/1986, de 10 de abril, de la Función Pública de la Comunidad de Madrid; art. 137.1 de la Ley 13/2015, de 8 de abril, de Función Pública de Extremadura; art. 61.1.b) de la Ley 6/1989, de 6 de julio, de la Función Pública Vasca; art. 122.4 de la Ley 4/2011, de 10 de marzo, del Empleo Público de CastillaLa Mancha (salvo que sea un funcionario o funcionaria que perdió la condición de servicios especiales y esté esperando la toma de posesión en el puesto asignado con ocasión del reingreso al servicio activo) y art. 102 de la Ley 3/2007, de 27 de marzo, de la Función Pública de la comunidad autónoma de las Islas Baleares.

25 Fecha de entrada en vigor de la Ley 13/1996, de 30 de diciembre, de medidas fiscales, administrativas y de orden social, que eliminó cualquier referencia a un plazo máximo en el art. 29.3.c) de la Ley 30/1984, de 2 de agosto, de Medidas para la Reforma de la Función Pública.

26 Art. 26.1.c) y 2 del Decreto Foral Legislativo 251/1993, de 30 de agosto, del Texto Refundido del Estatuto del Personal al Servicio de las Administraciones Públicas de Navarra.

27 Art. 2.4 de la Ley 2/1987, de 30 de marzo, de la Función Pública Canaria, salvo en aquellos aspectos reservados a la legislación básica del Estado o al desarrollo reglamentario de su autonomía organizativa; art. 1 de la Ley 4/1993, de 10 de marzo, reguladora de la Función Pública de la Administración de la Diputación Regional de Cantabria; art. 2., apartados 1 y 2.c), de la Decreto Legislativo 1/1997, de 31 de octubre, por el que se aprueba la refundición en un texto único de los preceptos de determinados textos legales vigentes en Cataluña en materia de función pública, así como art. 300.1 del Decreto Legislativo 2/2003, de 28 de abril, por el que se aprueba el texto refundido de la Ley municipal y de régimen local de Cataluña; art. 4.1.b) de la Ley 2/2015, de 29 de abril, del Empleo Público de Galicia; art. 2.1 y 3 de la Ley 3/1990, de 29 de junio, de Función Pública de la Administración Pública de la Comunidad Autónoma de la Rioja, y art. 1.1 del Ley $3 / 1985$, de 26 de diciembre, de Ordenación de la Función Pública de la Administración del Principado de Asturias. 
Canarias ${ }^{28}$ ), así como un plazo máximo de duración: en La Rioja, Cantabria e Islas Canarias se pierde la condición de funcionario o funcionaria por la falta de reincorporación al servicio activo una vez transcurridos más de diez años en situación de excedencia voluntaria por interés particular ${ }^{29}$; también en Asturias, con la peculiaridad de que el final del período de excedencia voluntaria debe ser advertido por la Administración y el interesado tiene un plazo de dos meses para solicitar la reincorporación al servicio activo, contado desde la fecha de finalización ${ }^{30}$.

Aparentemente el legislador básico estatal desautorizó este régimen legal autonómico porque:

1. la Ley 13/1996, 30 diciembre, de Medidas Fiscales, Administrativas y del Orden Social eliminó en el art. 29.3.c) de la Ley 30/1984 cualquier referencia a un plazo máximo de duración;

2. los arts. 63 a 67 del Estatuto Básico del Empleado Público contienen un exhaustivo y tasado listado de causas de pérdida de la condición de funcionario o funcionaria. Entre estas causas no se encuentra la falta de reingreso en el servicio activo por superación del plazo máximo de excedencia voluntaria por interés particular.

Éste fue el motivo por el que el Tribunal Constitucional declaró sobrevenida la inconstitucionalidad de los preceptos del (ahora derogado) texto refundido de la Ley de la Función Pública extremeña, aprobado por Decreto Legislativo 1/1990 de 26 julio, en la versión modificada parcial y urgentemente por la Ley 5/1995, de 20 de abril, que incluían como motivo de pérdida de condición de funcionario la falta de petición de reingreso al servicio activo durante el período de duración de la excedencia voluntaria. El Tribunal Constitucional consideró que esta ley autonómica carecía de competencia para tal regulación: 1) porque las causas de extinción de la relación funcionarial están enumeradas con carácter taxativo en la legislación estatal básica; y 2) porque las situaciones administrativas preservan precisamente la existencia del vínculo jurídico entre el funcionario y la Administración. El derecho a un cargo, destino o puesto de trabajo mantiene una estrecha relación con la regulación legal del reingreso en el servicio activo de aquellos funcionarios que no tienen garantizada la reserva del puesto de trabajo, y al ser la excedencia voluntaria por interés particular una situación administrativa que se otorga a instancia del interesado -o por una actuación tácita en tal sentido, en cuyo caso será declara de oficio-, debe ser el propio interesado quien ponga fin a la misma solicitando su reingreso al servicio activo (Fuentetaja y Gil 2018: 42 y 43; y Parada y Fuentetaja, 2015: 334).

Sin embargo, esta interpretación no es unánime. También se ha interpretado que corresponde a cada Administración imponer o no un plazo máximo de duración de la excedencia por interés particular, porque el art. 91 del Estatuto Básico del Empleado Público no impone un tiempo máximo de duración, sino que remite a las leyes de función pública la regulación de las condiciones de reingreso. Es decir, los defensores de esta criterio consideran que compete al legislador autonómico decidir si un mero interés particular puede amparar que la Administración se vea privada indefinidamente de su personal, o si impone al funcionario un límite temporal de no retorno ${ }^{31}$.

\subsubsection{Comunidades autónomas que establecen un plazo máximo de duración con rango reglamentario}

Por otro lado, las leyes de función pública de Galicia y Cataluña disponen que los funcionarios públicos en excedencia voluntaria por interés particular deberán permanecer en dicha situación un mínimo de uno o dos años, respectivamente, pero no establecen ningún plazo máximo de duración ${ }^{32}$. En Galicia el Decreto

28 Art. 45.5 de la Ley 3/1990, de 29 de junio, de Función Pública de la Administración Pública de la Comunidad Autónoma de la Rioja; art. 62.3 de la Ley 3/1985, de 26 de diciembre, de Ordenación de la Función Pública de la Administración del Principado de Asturias; art. 35.2.a) de la Ley 4/1993, de 10 de marzo, reguladora de la Función Pública de la Administración de la Diputación Regional de Cantabria y art. 39.5 de la Ley $2 / 1987$, de 30 de marzo, de la Función Pública Canaria.

29 Art. 45.5 de la Ley 3/1990, de 29 de junio, de Función Pública de la Administración Pública de la Comunidad Autónoma de la Rioja; art. 35.2.a) de la Ley 4/1993, de 10 de marzo, reguladora de la Función Pública de la Administración de la Diputación Regional de Cantabria, y art. $34.2^{\circ}$ de la Ley $2 / 1987$, de 30 de marzo, de la Función Pública Canaria, que expresa que deben ser diez años ininterrumpidos.

30 Art. 57.1.e) de la Ley 3/1985, de 26 de diciembre, de Ordenación de la Función Pública de la Administración del Principado de Asturias.

31 En este sentido, véase FUENTETAJA y GIL (2018: 82), así como STSJ del Principado de Asturias, Sala de lo Contenciosoadministrativo, Sección 1. a de 22 de mayo de 2017, Rec. 79/2017, FJ 2.

32 Art. 173.1 de la Ley 2/2015, de 29 de abril, del Empleo Público de Galicia y art. 86.2.a) del Decreto Legislativo 1/1997, de 31 de octubre, por el que se aprueba la refundición en un texto único de los preceptos de determinados textos legales vigentes en Cataluña en materia de función pública. 
92/1991, de 10 de marzo, por el que se aprueba el reglamento de situaciones administrativas de los funcionarios de la Administración de la comunidad autónoma de Galicia -aplicable también al personal al servicio de la Administración local ${ }^{33}$ - establece que no se podrá permanecer en excedencia voluntaria por interés particular más de diez años continuados ni menos de dos $^{34}$. En caso de no solicitar el reingreso antes del plazo de diez años, se producirá la pérdida de la condición de funcionario o funcionaria. El plazo máximo de diez años de permanencia deberá computarse a partir de la fecha de entrada en vigor de la Ley 80/1984, de 2 de agosto, de Medidas por la reforma de la Función Pública; mientras que el plazo mínimo de dos años deberá computarse desde el momento de la concesión de la excedencia voluntaria ${ }^{35}$. En Cataluña el Decreto $214 / 1990$, de 30 de junio, por el que se aprueba el reglamento del personal al servicio de las entidades locales establece que no podrán permanecer en excedencia voluntaria por interés particular menos de dos años ni más de diez años ${ }^{36}$.

La discrepancia de plazos mínimos de duración entre el reglamento y la ley gallega se resuelve directamente a favor de esta última, en virtud del principio de jerarquía normativa y derogación tácita ${ }^{37}$. Por lo que en Galicia los funcionarios deberán permanecer en excedencia voluntaria por interés particular un tiempo mínimo de un año. En Cataluña no cabe duda de que el período mínimo es de dos años.

La verdadera dificultad en ambas comunidades autónomas es determinar la duración máxima de este tipo de excedencia porque sus respectivas leyes de función pública no establecen ningún plazo, ni declaran expresamente que sea de duración indefinida. Simplemente obvian la cuestión. En estos ordenamientos el límite temporal de diez años lo fijan unas normas con rango reglamentario que han quedado obsoletas porque reproducen unas disposiciones legales ya derogadas.

Esta descoordinación normativa ha dado lugar a dos interpretaciones dispares, en función del orden jurisdiccional que se pronuncie al respecto. La primera teoría considera que al plazo máximo de duración establecido por reglamento autonómico se le puede achacar la misma invalidez que cuando lo impone una ley autonómica, porque una norma autonómica no puede crear una causa de pérdida de la condición de funcionario o funcionaria que no esté prevista en la legislación estatal básica. Incurre en vicio de incompetencia, como se comentó anteriormente. Además, la jurisdicción contencioso-administrativa interpreta que estos plazos reglamentarios han sido tácitamente derogados por el nuevo régimen legal. El primer pronunciamiento en este sentido fue en el ámbito de la Administración de Justicia. La Ley Orgánica 6/1985, de 1 de julio, del Poder Judicial no establece el plazo de duración de la situación administrativa de excedencia voluntaria por interés particular de los auxiliares y agentes judiciales. Por lo que el Tribunal Supremo estima que el plazo debe determinarse por remisión a la normativa sobre función pública. Éste fue el motivo por el que declaró ilegal y nulo de pleno derecho el art. 33.c) del Real Decreto 2003/1986 de 19 de septiembre, así como el art. 33.c) del Real Decreto 249/1996, de 16 de febrero, por el que se aprobaron sucesivos reglamentos orgánicos de los cuerpos de oficiales, auxiliares y agentes al servicio de la Administración de Justicia, pues establecían un período máximo de duración inferior al que dispone el art. 29.3.c) de la Ley 30/1984, de 2 de agosto, de Medidas para la reforma de la Función Pública. Además, consideró que el regulador no había justificado una desigualdad de trato entre los funcionarios de la Administración de Justicia y los de la Administración Pública en general ${ }^{38}$.

Mutatis mutandis, el Tribunal Superior de Justicia de Cataluña, el Juzgado de lo Contencioso-administrativo núm. 3 de Pontevedra, la Sala de lo Contencioso-administrativo del Tribunal Superior de Justicia de Galicia y el Tribunal supremo han trasladado este criterio al ámbito de la función pública local. Declaran inaplicables los límites temporales fijados por los reglamentos autonómicos porque han sido derogados los preceptos legales que los amparaban. Si el legislador ha eliminado el plazo máximo será porque quiere que ahora sea de duración indefinida. A mayor abundamiento, el Tribunal Superior de Justicia de Galicia considera que la duración de las excedencias voluntarias por interés particular concedidas conforme a

33 Art.1. ${ }^{\circ}$

34 Art. $\left.7 .^{\circ} \cdot \mathrm{c}\right)$.

35 Disposición transitoria primera.

36 Art. 193.

37 Art. 9.3 de la Constitución; art. 1 del Código Civil, art. 6 de la Ley Orgánica 6/1985, de 1 de julio, del Poder Judicial; art. 3.1 de la Ley 40/2015, de 1 de octubre, de Régimen Jurídico del Sector Público; art. 128.2 de la Ley 39/2015, de 1 de octubre, del Procedimiento Administrativo Común de las Administraciones Públicas, así como apdo. primero de la disposición transitoria primera de la Ley 2/2015, de 29 de abril, del Empleo Público de Galicia.

38 STS, Sala Tercera, de lo Contencioso-administrativo, Sección 7. a , de 28 de marzo de 2001, Rec. 8749/1996, FJ 4, y de 14 de julio de 2005, Rec. 6820/1999, FJ 4. 
REALA. Nueva Época - N. ${ }^{13}$, abril-septiembre 2020 - ISSN: 1989-8975 - DOI: 10.24965/reala.i13.10760 - [Págs. 93-109]

Excedencia voluntaria por interés particular en la función pública local: el reingreso al servicio activo

Mauricio Ruiz Ceniceros

las leyes derogadas se deben regir ahora por el nuevo régimen legal porque es más favorable para el interesado ${ }^{39}$.

Sin embargo, en la jurisdicción social encontramos la interpretación opuesta. Para acceder a la situación de desempleo procede comprobar si el empleado público cumple el requisito de solicitud de reingreso para considerarle en situación de desempleo. El criterio general es que, tras la reforma operada por la Ley 13/1996, de 30 de diciembre, una vez permanecido dos años en excedencia por interés personal el funcionario o funcionaria puede en cualquier momento instar su reincorporación a la Administración ${ }^{40}$. La discrepancia surge en Galicia porque su reglamento autonómico mantiene el límite de 10 años como plazo máximo de duración. La Sala de lo Social del Tribunal de Justicia de Galicia considera vigente dicho plazo reglamentario, hasta el punto de que la falta de solicitud de reingreso antes de su expiración conlleva la pérdida de la condición de funcionario y del derecho a estar en situación legal de desempleo ${ }^{41}$. Entiende que este desarrollo reglamentario sigue encajando en el vacío dejado por la legislación gallega.

\section{REINGRESO AL SERVICIO ACTIVO}

El derecho a un cargo, destino o puesto de trabajo y la garantía de la estabilidad en el empleo funcionarial está estrechamente relacionado con la concepción de las situaciones administrativas, porque aquel derecho se desvirtuaría si indirectamente estas pudieran determinar la pérdida de la condición de funcionario o funcionaria (Fuentetaja y Gil, 2018: 43). Sobre todo, en las situaciones administrativas que carecen de reserva al puesto de trabajo ${ }^{42}$. Por eso la efectividad de tal derecho exige vigilar que los requisitos exigidos y el procedimiento de reingreso no sean utilizados como impedimento indebido para la reincorporación al servicio activo.

En esta materia el Estatuto Básico del Empleado Público se remite al procedimiento y condiciones regulados reglamentariamente ${ }^{43}$, aunque nada impide que las leyes de función pública de las comunidades autónomas puedan singularizar su sistema de recuperación de la situación administrativa de servicio activo acorde con su propio sistema de provisión de puestos ${ }^{44}$. Ahora bien, si no existe una normativa específica en la correspondiente comunidad autónoma, ha de estarse a lo dispuesto en la regulación estatal ${ }^{45}$.

El primer requisito es que el interesado formule su solicitud de reingreso al servicio activo, porque la reincorporación nunca es automática ni se tramita de oficio. En la Administración General del Estado y en aquellas comunidades autónomas que no tengan normativa específica, el plazo para resolver las solicitudes de reingreso es de tres meses y el silencio administrativo negativo ${ }^{46}$. También en la Comunidad Valenciana

39 STSJ de Cataluña, Sala de lo Contencioso-administrativo, Sección 4. a de 5 de julio de 2012, Rec. 210/2011, FJ 5; SJCA núm. 3 de Pontevedra, de 19 de septiembre de 2016, P. A. 135/2016, FJ 2; STSJ de Galicia, Sección 1. a de la Sala de lo Contenciosoadministrativo, de 26 de abril de 2017, Rec. 446/2016, FJ 5, y providencia de la Sección 1. ${ }^{\text {a }}$ de la Sala de lo Contencioso-administrativo del TS, de 25 de enero de 2018, Rec. núm. 4658/2017, por la que inadmitió el recurso de casación al no apreciar en interés casacional objetivo ni la conveniencia de su pronunciamiento. Si la norma aplicada retroactivamente fuese desfavorable, es decir impusiera un plazo menor, se aplicaría la vigente en la fecha de concesión de la excedencia (STS, Sala Tercera, de lo Contencioso-administrativo, Sección 7.a de 27 de abril de 2005, Rec. 4391/1999, FJ 3).

40 STSJ de Madrid, Sala de lo Social, Sección 4. a de 24 de abril de 2001, Rec. 1239/2001, FJ 1.

41 Art. 267.2.d) del Real Decreto Legislativo 8/2015, de 30 de octubre, por el que se aprueba el texto refundido de la Ley General de la Seguridad Social y STSJ de Galicia, Sala de lo Social, de 19 de marzo de 2013, Rec. 561/2010, FJ 3, así como STSJ de Galicia, Sala de lo social, de 31 de enero de 2014, Rec. 6079/2011, FJ 2 y 3 , y de 30 de mayo de 2014, Rec. 4013/2012, FJ 2 y 3.

42 En este sentido véase PARADA y FUENTETAJA (2015: 334) y FUENTETAJA (2013: 546), así como STSJ del País Vasco, Sala de lo Contencioso-administrativa, Sección $1 .^{\text {a }}$, de 2 de julio de 2001, Rec. 40/2001, FJ 4.

43 Art. 91, pero a falta de dicho desarrollo reglamentario se rige por el art. 29 bis de la Ley 30/1984, de 2 de agosto, de Medidas para la reforma de la Función Pública y el art. 62 Real Decreto 364/1995, de 10 de marzo, por el que se aprueba el Reglamento General de Ingreso del Personal al servicio de la Administración general del Estado y de Provisión de Puestos de Trabajo y Promoción Profesional de los Funcionarios Civiles de la Administración general del Estado.

44 FUENTETAJA y GIL (2018: 82) considera que el Estatuto Básico del Empleado Público no «deslegaliza» la regulación del reingreso al servicio activo, sino tan sólo tres aspectos de dicha operación: plazos, procedimientos y condiciones.

45 En todo caso, el art. 63 del Decreto de 30 de mayo de 1952 por el que se aprueba el texto del Reglamento de funcionarios de la Administración local ha sido tácitamente derogado por el apdo. 2 de la disposición derogatoria y el art. 140 del texto refundido de disposiciones legales vigentes en materia de régimen local, aprobado por Real Decreto Legislativo 781/1986, de 18 de abril. También ha sido derogado por el art. 29 bis de la Ley 30/1984, de 2 de agosto, de Medidas para la reforma de la Función Pública, en la que se contempla una regulación diferente a la que recogía aquel precepto reglamentario (STSJ de Aragón, Sala de lo Contencioso-administrativo, Sección 2. a , de 27 de marzo de 2002, Rec. 104/2001, FJ 6).

46 Art. 2.a) y k) del Real Decreto 1777/1994, de 5 de agosto, de adecuación de las normas reguladoras de los procedimientos de gestión de personal a la Ley 30/1992, de 26 de noviembre, de Régimen Jurídico de las Administraciones Públicas y del Procedimiento 
la solicitud de reingreso por adscripción provisional debe ser resuelta en el plazo de tres meses, transcurrido el cual se debe entender desestimada ${ }^{47}$; así como en Cataluña, donde el silencio administrativo es negativo, pero el plazo de resolución es de 30 días $^{48}$.

El segundo requisito es que exista un puesto vacante ${ }^{49}$. Es decir, el funcionario o funcionaria en excedencia no puede ser nombrado con carácter interino ni puede ser contratado para sustituir de manera transitoria al titular de una plaza (por ejemplo, por baja), porque tal plaza no estará vacante. Tiene que esperar a que exista vacante en la escala y cuerpo que le corresponda y, una vez acontezca dicha situación, participar en la provisión por el sistema de concurso o libre designación para su adscripción definitiva o temporal ${ }^{50}$.

Además, no se trata de un derecho preconfigurado y determinado cuya ejecución dependa exclusivamente de la solicitud de reingreso, ni obedece a una mera comprobación administrativa de aspectos reglados o de control a meros efectos de constancia. La efectividad del derecho pende de la existencia de una plaza a la que reingresar dotada presupuestariamente ${ }^{51}$, aunque la suya originaria haya sido amortizada ${ }^{52}$, a partir de lo cual se abren dos tipos de sistemas o procedimientos de reingreso ${ }^{53}$.

\subsection{Concurso o libre designación}

El procedimiento normal u ordinario de reingreso es mediante la participación del funcionario o funcionaria en las convocatorias de concurso, en el que el interesado debe acreditar que posee más méritos que los demás funcionarios para acceder a la plaza ${ }^{54}$. También puede ser por libre designación para la provisión de puestos de trabajo ${ }^{55}$. En ambos casos el interesado está obligado a concurrir si quiere reingresar ${ }^{56}$. Aunque su reincorporación puede ser postergada por otros concursantes con preferencia: en las comunidades autónomas de las Islas Canarias y Galicia los excedentes forzosos, suspensos y excedentes voluntarios para atender al cuidado de hijos, o en servicio en otros organismo o entidades del sector público, o en servicios especiales tendrán preferencia por una sola vez frente a los excedentes por interés particular ${ }^{57}$; en

Administrativo Común. En este sentido, STSJ del País Vasco, Sala de lo Contencioso-administrativo, Sección 3. ${ }^{a}$, de 31 de diciembre de 2003, Rec. 412/2003, FJ 5; STSJ de la Comunidad Valenciana, Sección 2. ${ }^{\text {a }}$, Sala de lo Contencioso-administrativo, de 30 de octubre de 2013, Rec. 676/2011, FJ 2, y STSJ de Andalucía de Granada, Sección 3. ${ }^{a}$, Sala de lo Contencioso-administrativo, de 17 de noviembre de 2014, Rec. 1574/2010, FJ 1.

47 Apdo. 2 de la disposición adicional vigésimo segunda de la Ley 10/2010, de 9 de julio, de la Generalitat, de Ordenación y Gestión de la Función Pública Valenciana.

48 Art. 221 del Decreto 214/1990, de 30 de junio, por el que se aprueba el Reglamento del personal al servicio de las entidades locales de Cataluña.

49 Así lo entienden LORENZO (2004: 338) y la STSJ de Castilla y León de Valladolid, Sala de lo Contencioso-administrativo, Sección 1.a , de 29 de mayo de 2019, Rec. 67/2019, FJ 4.

50 STSJ de la Región de Murcia, Sala de lo Contencioso-administrativo, de 23 de marzo de 2016, Rec. 286/2015, FJ 4.

51 STSJ de Madrid, Sección 7. ${ }^{\text {, }}$, Sala de lo Contencioso-administrativo, de 22 de enero de 2018, Rec. 85/2017, FJ 4.

52 STSJ de la Comunidad Valenciana, Sala de lo Contencioso-administrativo, Sección 2. a, de 3 de mayo de 2017, Rec. 452/2014, FJ 3.

53 En este sentido se pronuncian PARADA y FUENTETAJA (2015: 334) y la STSJ del Principado de Asturias, Sala de lo Contencioso-administrativo, Sección 1. ${ }^{a}$, de 18 de marzo de 2019, Rec. 907/2017, FJ 2.

54 STSJ de Madrid, Sala de lo Contencioso-administrativo, Sección 7. a, de 3 de marzo de 2014, Rec. 514/2012, FJ 3.

55 Art. 29 bis 1 de la Ley 30/1984, de 2 de agosto, de Medidas para la reforma de la Función Pública; art. 59.1 del Real Decreto 128/2018, de 16 de marzo, por el que se regula el régimen jurídico de los funcionarios de Administración local con habilitación de carácter nacional; art. 62.1 del Real Decreto 364/1995, de 10 de marzo, por el que se aprueba el Reglamento general de ingreso del personal al servicio de la Administración General del Estado y de provisión de puestos de trabajo y promoción profesional de los funcionarios civiles de la Administración General del Estado; art. 33.2 de la Decreto Legislativo 1/1991, de 19 de febrero, por el que se aprueba el Texto Refundido de la Ley de Ordenación de la Función Pública de la Comunidad Autónoma de Aragón; art. 89.2 de la Ley 7/2005, de 24 de mayo, de la Función Pública de Castilla y León; arts. 76.2 y 126.2 de la Ley 4/2011, de 10 de marzo, del Empleo Público de Castilla-La Mancha; art. 70.1.a) del Decreto Legislativo 1/1997, de 31 de octubre, por el que se aprueba la refundición en un texto único de los preceptos de determinados textos legales vigentes en Cataluña en materia de función pública; art. 218.1) del Decreto 214/1990, de 30 de junio, por el que se aprueba el Reglamento del personal al servicio de las entidades locales de Cataluña; art. 136.1 de la Ley 10/2010, de 9 de julio, de la Generalitat, de Ordenación y Gestión de la Función Pública Valenciana; art. 66.1 de la Ley 1/1986, de 10 de abril, de la Función Pública de la Comunidad de Madrid; art. 146.1 de la Ley 13/2015, de 8 de abril, de Función Pública de Extremadura; art. 178.2 de la Ley 2/2015, de 29 de abril, del Empleo Público de Galicia, así como arts. 7.1.c) y 9.a) del Decreto 92/1991, de 10 de marzo, por el que se aprueba el Reglamento de situaciones administrativas de los funcionarios de la Administración de la Comunidad Autónoma de Galicia; art. 113.1 de la Ley 3/2007, de 27 de marzo, de la Función Pública de la comunidad autónoma de las Islas Baleares; y art. 68.2 de la Ley 6/1989, de 6 de julio, de la Función Pública Vasca.

56 STSJ de Castilla y León de Valladolid, Sala de lo Contencioso-administrativo, Sección 1. a de 29 de mayo de 2019 , FJ 4.

57 Art. 44 de la Ley 2/1987, de 30 de marzo, de la Función Pública Canaria y art. 9.A) del Decreto 92/1991, de 10 de marzo, por el que se aprueba el Reglamento de situaciones administrativas de los funcionarios de la Administración de la Comunidad Autónoma de Galicia. 
las Islas Baleares y en el País Vasco tienen preferencia quienes provienen de la situación de expectativa de destino, excedencia forzosa y suspensión ${ }^{58}$; y en Cantabria, Cataluña y Asturias los excedentes forzosos y los suspensos tienen preferencia sobre los excedentes voluntarios, y estos a su vez sobre todos los que se encuentren en otras situaciones ${ }^{59}$. Además, en Cataluña los funcionarios que soliciten el reingreso mediante la participación en concursos disfrutarán del derecho preferente, por una sola vez, para ocupar alguna de las vacantes correspondientes a su cuerpo o escala que haya en la localidad donde servían en el momento de producirse el cese ${ }^{60}$.

En este sistema de reingreso no es necesario que el reincorporado reúna los requisitos del puesto de trabajo. Ningún cuerpo normativo regula la exigencia de que tenga que superar pruebas médicas para acceder al servicio activo, como si se tratara de un personal que accede por primera vez a la función pública. El Tribunal Superior de Justicia de Cataluña ha llegado a afirmar que, aunque la plaza en cuestión sea la de bombero, el interesado tenga 56 años y sea evidente que a esa edad no se conservan las condiciones físicas previstas para el acceso a tal función pública, no se puede condicionar su reingreso a la superación de un examen médico. No cabe hacer una interpretación extensiva del régimen de reingreso por adscripción provisional (en el que sí procede tal comprobación) con la reincorporación al puesto de origen por concurso, en el que la persona funcionaria ya mostró mérito y capacidad de desempeñar su puesto y, por tanto, no es precisa nueva valoración al reingresar en él ${ }^{61}$.

Si durante la excedencia el funcionario perdió su capacidad inicialmente demostrada, no procede someterlo a un sistema de valoración como si de un «no funcionario» se tratara, en el que finalmente se decida su no incorporación. Tal decisión se debe ajustar a las previsiones y procedimientos establecidos en caso de incapacidad para el ejercicio de la función pública, sólo apreciable de oficio si la persona interesada se encuentra en servicio activo, o si lo pide voluntariamente. Lo contrario supondría dejar al arbitrio de la Administración la posibilidad de reingresar al servicio activo, «[...] que constituye, por contra, un auténtico derecho del funcionario, que no puede verse frustrado por la imposición de requisitos o exigencias que no se regulan en ninguna parte $[\ldots]{ }^{62}$, y dejar al funcionario o funcionaria en una "[...] situación injustificadamente insalvable, derivada, precisamente de su condición de funcionario: no se encontraría en activo porque la Administración valora que es incapaz, pero no puede ser declarada su incapacidad a iniciativa de la Administración en la forma prevista para los funcionarios, porque no se encuentra en activo [...]» ${ }^{63}$. Por tanto, el reingreso mediante participación en concurso o libre designación no requiere ninguna comprobación o declaración de aptitud.

Ahora bien, la contundencia de esta afirmación decae cuando se trate de puestos singularizados, es decir aquellos que exigen la adquisición y mantenimiento de una capacidad y conocimientos específicos. Entonces prevalece la necesidad de reevaluar su capacidad y conocimientos ${ }^{64}$. A este respecto, en Castilla-La Mancha los funcionarios de las entidades locales deben asistir a las actividades obligatorias que se programen para adquirir o perfeccionar los conocimientos, habilidades o destrezas adecuados para el desempeño de las funciones o tareas propias del puesto de trabajo que ocupe o vaya a ocupar con ocasión del reingreso al servicio activo ${ }^{65}$.

58 Art. 113.3 de la Ley 3/2007, de 27 de marzo, de la Función Pública de la comunidad autónoma de las Islas Baleares y art. 68.1 de la Ley 6/1989, de 6 de julio, de la Función Pública Vasca.

59 Art. 40.1 de la Ley 4/1993, de 10 de marzo, reguladora de la Función Pública de la Administración de la Diputación Regional de Cantabria; art. 222 del Decreto 214/1990, de 30 de junio, por el que se aprueba el Reglamento del personal al servicio de las entidades locales de Cataluña y art. 67.1 de la Ley 3/1985, de 26 de diciembre, de Ordenación de la Función Pública de la Administración del Principado de Asturias.

60 Art. 220 del Decreto 214/1990, de 30 de junio, por el que se aprueba el Reglamento del personal al servicio de las entidades locales de Cataluña.

61 La adscripción provisional está regulada en el apdo. 2 del art. 29 bis de la Ley 30/1984, de 2 de agosto, de Medidas para la reforma de la Función Pública, en el que se prevé tal requisito cuando el funcionario haya accedido a la Administración conforme a un mérito y capacidad que no sirve para el nuevo puesto al que es provisionalmente adscrito. Por eso es necesaria la valoración ad hoc con el fin de comprobar si también reúne los requisitos para el nuevo puesto, regulada en el apdo. 1 del art. 29 bis de la Ley 30/1984.

62 STSJ de Cataluña, Sala de lo Contencioso-administrativo, Sección 4. ${ }^{a}$, de 5 de junio de 2015, Rec. 20/2015, FJ 7.

63 STSJ de Aragón, Sala de lo Contencioso-administrativo, Sección 3. a , de 27 de marzo de 2014, Rec. 333/2010, FJ 3.

64 Por ejemplo, en el ámbito de la Administración de Justicia el art. 359 de la Ley Orgánica 6/1985, de 1 de julio, del Poder Judicial exige informes, actuaciones de comprobación y declaración de aptitud para el reingreso en el servicio activo del juez o magistrado en excedencia voluntaria por interés particular de duración superior a 10 años, tras la reforma operada por la Ley Orgánica 19/2003, de 23 de diciembre.

65 Art. 112 de la Ley 4/2011, de 10 de marzo, del Empleo Público de Castilla-La Mancha. 


\subsection{Adscripción provisional}

Es el procedimiento extraordinario o de gracia, consistente en la adscripción del funcionario a un puesto de carácter provisional por tiempo no superior a un año, condicionado a que reúna los requisitos para el desempeño de ese puesto y lo permitan las necesidades del servicio. Durante el referido plazo se convocará la provisión definitiva del puesto asignado, debiendo el funcionario reingresado con destino provisional participar en la convocatoria. Si en esta convocatoria no obtuviere el destino definitivo quedará a disposición del correspondiente organismo, que le asignará otro puesto provisional correspondiente a su cuerpo o escala ${ }^{66}$.

La duda surge con el carácter reglado o discrecional de este sistema excepcional, con distintas opiniones: por un lado, algunos autores consideran que el funcionario o funcionaria nunca tiene derecho a exigirlo ${ }^{67}$; por su parte, el Tribunal Superior de Justicia de Aragón coincide en que el peticionario carece de un derecho subjetivo al reingreso directo, pero solo porque está condicionado a las necesidades del servicio, «[...] lo que abona un carácter más discrecional, no arbitrario, pero tampoco estrictamente reglado» ${ }^{68}$; y, por último, el Tribunal Superior de Justicia de Madrid estima que la Administración ha de valorar si las necesidades del servicio justifican la adscripción provisional del interesado a una plaza, o por el contrario procede remitirle al siguiente concurso ${ }^{69}$. Atendiendo a la literalidad de la norma, parece que la respuesta correcta es que el requisito de las necesidades del servicio es un concepto jurídico indeterminado que concurre o no concurre en cada caso. Por ello, si no cabe el reingreso por el sistema ordinario ${ }^{70}$, entra en juego la posibilidad de adscribir provisionalmente al funcionario o funcionaria a un puesto de trabajo vacante para el que reúna los requisitos legalmente establecidos y cuando así lo justifiquen las necesidades del servicio. La Administración no es omnipotente para apreciar el cumplimiento de estas condiciones, sino que debe estimar su existencia o no en atención a los presupuestos fácticos concurrentes. De modo que si existen plazas vacantes con dotación presupuestaria y concurren en el solicitante los requisitos para desempeñar el puesto de trabajo, «[...] la Administración no tiene otra opción que acordar al adscripción provisional, al no ser absolutamente libre con base a criterios de oportunidad sino que debe observar de manera reglada en función de los presupuestos fácticos determinantes ${ }^{71}$. Ni siquiera la disimilitud en el contenido de las funciones desempeñadas originariamente por el funcionario excedentario y las que corresponden a la plaza sin proveer justifica la denegación del reingreso, porque tal razón carece de amparo jurídico en los preceptos aplicables $^{72}$.

66 Art. 29 bis 2 y 3 de la Ley 30/1984, de 2 de agosto, de Medidas para la reforma de la Función Pública; así como art. 59.1 del Real Decreto 128/2018, de 16 de marzo, por el que se regula el régimen jurídico de los funcionarios de Administración Local con habilitación de carácter nacional; arts. 62.2 y 63.c) del Real Decreto 364/1995, de 10 de marzo, por el que se aprueba el Reglamento general de ingreso del personal al servicio de la Administración General del Estado y de provisión de puestos de trabajo y promoción profesional de los funcionarios civiles de la Administración General del Estado; art. 33.2 y 3 de la Decreto Legislativo 1/1991, de 19 de febrero, por el que se aprueba el Texto Refundido de la Ley de Ordenación de la Función Pública de la Comunidad Autónoma de Aragón; art. 89.3 de la Ley 7/2005, de 24 de mayo, de la Función Pública de Castilla y León; art. 126.2 de la Ley 4/2011, de 10 de marzo, del Empleo Público de Castilla-La Mancha; art. 70.1.a) del Decreto Legislativo 1/1997, de 31 de octubre, por el que se aprueba la refundición en un texto único de los preceptos de determinados textos legales vigentes en Cataluña en materia de función pública, así como arts. 218.b) y 219 del Decreto 214/1990, de 30 de junio, por el que se aprueba el Reglamento del personal al servicio de las entidades locales de Cataluña; art. 136.2 de la Ley 10/2010, de 9 de julio, de la Generalitat, de Ordenación y Gestión de la Función Pública Valenciana; art. 66.2 de la Ley 1/1986, de 10 de abril, de la Función Pública de la Comunidad de Madrid; art. 146.1 de la Ley 13/2015, de 8 de abril, de Función Pública de Extremadura; art. 178.3 de la Ley 2/2015, de 29 de abril, del Empleo Público de Galicia, así como art. 9.A) del Decreto 92/1991, de 10 de marzo, por el que se aprueba el Reglamento de situaciones administrativas de los funcionarios de la Administración de la Comunidad Autónoma de Galicia; art. 113.2 de la Ley 3/2007, de 27 de marzo, de la Función Pública de la Comunidad Autónoma de las Islas Baleares; y art. 68.3 de la Ley 6/1989, de 6 de julio, de la Función Pública Vasca.

67 Véase PARADA VÁZQUEZ, R. y FUENTETAJA PASTOR, J. A. (2015: 335), aunque esta afirmación ya no es exacta porque cuando el art. 59.1 del Real Decreto 128/2018, de 16 de marzo, por el que se regula el régimen jurídico de los funcionarios de Administración local con habilitación de carácter nacional enumera los sistemas de reingreso de servicio activo de aquellos que no tengan reserva de puesto, invierte el orden de enumeración: «[...] se efectuará a través de la solicitud de un nombramiento provisional, o la participación en un concurso de traslados o en un procedimiento de libre designación». Es decir, parece otorgar prevalencia al nombramiento provisional.

68 STSJ de Aragón, Sala de lo Contencioso-administrativo, Sección 3. ${ }^{a}$, de 5 de diciembre de 2016, FJ 3.

69 STSJ de Madrid, Sección 7. a, Sala de lo Contencioso-administrativo, de 22 de enero de 2018, Rec. 85/2017, FJ 4.

70 Porque todavía no se hayan sacado a concurso las plazas o mientras el concurso se resuelve. FJ 3 y 4 .

71 STSJ del Principado de Asturias, Sala de lo Contencioso-administrativo, Sección 1. a , de 18 de marzo de 2019, Rec. 907/2017,

72 STSJ de Andalucía de Granada, Sala de lo Contencioso-administrativo, Sección 3. a, de 14 de noviembre de 2018, Rec. 897/2018, FJ 3 y 4. 
Ahora bien, el Tribunal Superior de Justicia de Andalucía con sede en Sevilla estima que la adscripción provisional exige que el funcionario o funcionaria reúna los requisitos para el desempeño del puesto, porque si a los funcionarios en activo (por ejemplo, policiales) se les exige unos especiales condicionamientos físicos y psíquicos para mantenerse en el desempeño de sus puestos, el solicitante de reingreso también deberá acreditar previamente, en interés del servicio, que reúne las condiciones psico-físicas indispensables para el desempeño del puesto provisional ${ }^{73}$. Interpretación del que resulta un régimen totalmente contrapuesto al considerado en el reingreso mediante concurso.

Además, no basta con que la plaza esté vacante y dotada presupuestariamente, sino que es preciso que la cobertura provisional venga exigida por necesidades de servicio. Por lo que, siendo la regla el concurso y la excepción la adscripción provisional, no resulta necesaria una motivación concreta que excluya la necesidad del servicio en una determinada plaza para denegar su adscripción provisional. Los Tribunales Superiores de Justicia de Andalucía y de Madrid estiman que el funcionario carece del derecho a obtenerla porque la asignación provisional de la plaza constituye una manifestación de las potestades de autoorganización al servicio del principio de eficacia ${ }^{74}$. Aunque la noción de necesidades del servicio constituya un concepto jurídico indeterminado, la Administración goza de cierto margen de libertad en su apreciación pues la adscripción supone un procedimiento excepcional en el que el funcionario carece de derecho subjetivo a la asignación de determinada plaza. Únicamente tiene derecho a solicitar su reingreso, pero no se precisa motivación concreta para excluir la necesidad del servicio en una determinada plaza para denegar la adscripción, porque la regla es el concurso y la adscripción provisional es la excepción ${ }^{75}$.

$\mathrm{Ni}$ siquiera el hecho de que la Administración saque a concurso una plaza y quede vacante -porque los aspirantes no alcancen el mínimo establecido en las bases de la convocatoria- constituye prueba suficiente para considerar que su adscripción provisional sea necesaria para el servicio. El solicitante debe acreditar que la cobertura de ese puesto de trabajo es imprescindible para el buen funcionamiento del servicio, de acuerdo con la carga de trabajo y necesidades de todas las unidades y departamentos del organismo ${ }^{76}$. Es decir, no se debe confundir conveniencia con necesidad.

Otro problema es qué sucede si, efectivamente, en el plazo de un año la Administración convoca el concurso para la provisión definitiva del puesto y el funcionario o funcionaria en excedencia cumple su obligación de participar en la convocatoria, pero no obtiene el destino definitivo, porque nada garantiza que lo vaya a conseguir. «espinoso» problema que no aborda de la legislación básica del Estado (Parada y Fuentetaja, 2015: 335). Atendiendo al contexto regulatorio el Tribunal Superior de Justicia de Asturias interpreta que el funcionario en excedencia seguirá a disposición del órgano competente en destino provisional ${ }^{77}$, es decir que tiene derecho a que después se le asignen sucesivos puestos provisionales.

Cuando existan varios puestos de trabajo ubicados en distintas localidades, el funcionario o funcionaria en excedencia tampoco ostenta un derecho a incorporarse a la plaza que estime conveniente según sus propios intereses, porque la adscripción provisional queda circunscrita a la concurrencia de los siguientes requisitos; existencia de vacante; necesidades de servicio y aptitud para el desempeño. No puede exigir a la Administración una adscripción directa a un determinado destino ${ }^{78}$.

\subsection{Amortización de plaza vacante}

Ahora bien, lo cierto es que la Administración no siempre está abocada a articular el reingreso si su intención es amortizar la plaza vacante. En uso de su potestad organizativa, puede optar por amortizar la plaza a ocupar por el excedente reingresado, como alternativa a la convocatoria del oportuno concurso para su provisión definitiva en el plazo de un año ${ }^{79}$. Un requisito imprescindible para que se produzca el reingreso al servicio activo es que exista una plaza en la que reingresar, lo cual depende de la potestad de autoorganización de cada Administración, que dispone de libertad suficiente para reordenar sus servicios de la forma

\footnotetext{
73 STSJ de Andalucía de Sevilla, Sala de lo Contencioso-administrativo, Sección 1. a, de 29 de abril de 2019, Rec. $62 / 2019$, FJ 2.

74 STSJ de Andalucía de Sevilla, Sala de lo Contencioso-administrativo, Sección 2. a, de 9 de marzo de 2017 , Rec. $798 / 2014$.

75 STSJ de Madrid, Sala de lo Contencioso-administrativo, Sección 7. a , de 23 de noviembre de 2015, Rec. 181/2014, FJ 2.

76 STSJ de Madrid, Sala de lo Contencioso-administrativo, Sección 7. a de 3 de marzo de 2014, Rec. 514/2012, FJ 3.

77 STSJ del Principado de Asturias, Sala de lo Contencioso-administrativo, Sección 1.a , de 18 de marzo de 2019, Rec. $907 / 2017$,

78 STSJ del Principado de Asturias, Sala de lo Contencioso-administrativo, Sección 1. a , de 18 de marzo de 2019, Rec. $907 / 2017$,

79 STSJ de Aragón, Sala de lo Contencioso-administrativo, Sección 2. ${ }^{a}$, de 27 de marzo de 2002, Rec. 104/2001, FJ 6.
} FJ 2. FJ 2. 
que estime más oportuna. Es decir, el eventual reingreso de funcionarios que estén en excedencia no puede condicionar esa potestad de autoorganización, pero sí al contrario: la potestad de organización de los servicios permite condicionar el reingreso hasta el punto de dificultarlo o retrásalo.

Por lo que es posible que el funcionario en excedencia consiga una resolución administrativa o una sentencia estimatoria que declare su derecho al reingreso, pero la efectividad de tal declaración quedará en papel mojado cuando la Administración amortice las plazas vacantes y no convoque concurso de nuevas plazas, provocando una excedencia «forzada». Para prevenir este fraude de ley la Administración debe estar sujeta a un límite: no puede impedir el reingreso bajo el amparo formal de una supuesta falta de plaza, cuando tal ausencia de plazas haya sido generada mediante una actuación ilegal de la propia Administración ${ }^{80}$.

\section{CONCLUSIONES FINALES}

En definitiva, el régimen jurídico de la excedencia voluntaria por interés particular no se ajusta a los principios de buena regulación, porque las sucesivas reformas normativas han generado un entorno de incertidumbre que dificulta a los funcionarios de la Administración local adoptar decisiones en esta materia.

El problema no es el requisito del plazo mínimo de permanencia, pues tanto la legislación estatal como las leyes autonómicas lo regulan expresamente (entre dos años y ninguno). La duda surge con el plazo máximo de duración, porque su regulación padece una manifiesta descoordinación y obsolescencia legal y reglamentaria. Las últimas reformas de la legislación básica estatal han eliminado toda referencia expresa un límite temporal máximo, a pesar de lo cual todavía siguen existiendo disposiciones legales y reglamentarias que lo conservan.

En el primer supuesto se encuentran las comunidades autónomas de La Rioja, Cantabria, Islas Canarias y Asturias, donde sus propias leyes autonómicas prevén expresamente que la no incorporación al servicio activo transcurrido un tiempo superior a diez años es causa de pérdida de la condición de funcionario o funcionaria. Tal regla cumple el requisito de rango legal que el Estatuto Básico del Empleado Púbico exige a las comunidades autónomas para regular esta materia, por lo que, desde este punto de vista, es una norma válida y vinculante.

Sin embargo, esta opinión no es unánime porque la pérdida de condición de funcionario por vencimiento del plazo máximo de excedencia voluntaria por interés particular no es un supuesto tipificado en la legislación básica. No se puede perder la condición de funcionario por un motivo que no esté previsto en el Estatuto Básico del Empleado Público.

La incertidumbre se agrava cuando el límite temporal máximo de este tipo de excedencia no lo establece una norma con rango de ley, sino una disposición reglamentaria. No sólo hay pocos pronunciamientos judiciales que aborden el tema, sino que además mantienen criterios dispares en función de la jurisdicción involucrada. Los Tribunales de la jurisdicción contencioso-administrativa estiman que los principios de legalidad y jerarquía normativa suponen la inaplicabilidad o derogación tácita del plazo máximo todavía expresado reglamentariamente, porque carece de amparo legal y no está tipificado como causa de pérdida de la condición de funcionario o funcionaria público. Es decir, los funcionarios de la Administración local con habilitación de carácter nacional y los funcionarios de las entidades locales con sede en Andalucía, Región de Murcia, Castilla y León, Comunidad Valenciana, Comunidad de Madrid, País Vasco, Cataluña, Aragón, Extremadura, Castilla-La Mancha, Galicia, Navarra y las Islas Baleares pueden permanecer en situación de excedencia voluntaria por interés particular por tiempo indefinido y solicitar el reingreso en cualquier momento posterior al plazo mínimo de permanencia.

Pero la Sala de lo Social del Tribunal Superior de Justicia de Galicia discrepa porque sigue aplicando el plazo máximo reglamentario de 10 años, de modo que la persona funcionaria que no solicite el reingreso antes del vencimiento pierde el derecho a estar en situación de desempleo.

El segundo problema es el procedimiento de reingreso. La regla general es que debe ser mediante convocatoria de concurso o libre designación, en el que los Tribunales Superiores de Justicia de Aragón y Cataluña entienden que el funcionario o funcionaria en excedencia tiene derecho a participar sin necesidad de superar nuevas pruebas de acceso: sólo tiene que acreditar que posee más méritos que los demás funcionarios concurrentes. Aunque este criterio flaquea en puestos singularizados, es decir aquellos que exigen la adquisición y mantenimiento de una capacidad y conocimientos específicos.

80 Véase PARADA y FUENTETAJA (2015: 335), que cita la STSJ de Castilla-La Mancha de 1 de octubre de 1998. 
El sistema alternativo de reingreso es la adscripción provisional, que teóricamente es obligatorio para la Administración si hay plazas vacantes con dotación presupuestaria. Sin embargo, en la práctica puede ser obstaculizado cuando la Administración alegue que no existen necesidades del servicio, o exija la acreditación de las condiciones psico-físicas y de formación que requiera el desempeño del puesto.

Además, la Administración siempre puede amortizar cualquier plaza vacante, frente a lo cual la oposición del interesado sólo prosperará si consigue acreditar judicialmente que, en realidad, la ausencia de plazas ha sido generada por la propia Administración en fraude de ley. Es decir, la Administración cuenta con suficiente margen de actuación para demorar la reincorporación del funcionario o funcionaria en excedencia voluntaria por interés particular.

\section{REFERENCIAS BIBLIOGRÁFICAS}

DE LA VALLINA VELARDE, J. L. (1962): "Las situaciones administrativas de los funcionarios públicos", en Revista de Administración Pública, núm. 39, págs. 463-486.

FUENTETAJA PASTOR, J. A. (2010): "Función pública local”, en FUENTETAJA PASTOR, J. A.; FERNÁNDEZ RODRÍGUEZ, C. (dirs.): Manual de Derecho Local Madrid, págs. 339-401. Madrid: Editorial lustel, 1. ${ }^{a}$ ed.

FUENTETAJA PASTOR, J. A. (2013): "Situaciones administrativas", en SÁNCHEZ MORÓN, M. (coord.): Régimen jurídico de la función pública, págs. 287-500. Pamplona: Lex Nova.

FUENTETAJA PASTOR, J. A.; GIL FRANCO, A. J. (2018): La configuración de la relación jurídica de los empleados públicos locales: situaciones administrativas, vacaciones, permisos y licencias. Granada: CEMCI Publicaciones.

GAMERO CASADO, E.; FERNÁNDEZ RAMOS, S. (2018): Manual Básico de Derecho Administrativo. Madrid: Editorial Tecnos, 15. ${ }^{a}$ ed

GARCÍA-TREVIJANO FOS, J. A. (1954): "Relación orgánica y relación de servicios en los funcionarios públicos”, en Revista de Administración Pública, núm. 13, págs. 53-102.

LORENZO DE MEMBIELA, J. B. (2004): Las Situaciones Administrativas de los Funcionarios Públicos. Cizur Menor (Navara): Editorial Aranzadi.

LORENZO DE MEMBIELA, J. B. (2005): Permisos, Licencias y Situaciones Administrativas de los Funcionarios Públicos. Manual práctico de la función pública. Cizur Menor (Navarra): Editorial Aranzadi, 1. ${ }^{\text {a }}$ ed.

MANZANA LAGUARDA, R. (1998): Situaciones administrativas de los funcionarios públicos. Valencia: Ediciones Revista General del Derecho.

MARTÍNEZ DE PISÓN APARICIO, I. (1995): Régimen jurídico de la función pública y derecho al cargo. Madrid: Cívitas.

MORILLO-VELARDE PÉREZ, J. I. (1985): "Las situaciones administrativas de los funcionarios en la Ley de Medidas para la reforma de la Función Pública", en Revista española de derecho administrativo, núm. 48, págs. 525-562.

PARADA VÁZQUEZ, R.; FUENTETAJA PASTOR, J. A. (2015): Derecho de la función Pública. Madrid: OPEN Ediciones Universitarias, S. L.

\section{ANEXO JURISPRUDENCIA}

STC 1/2003, Pleno, de 16 de enero de 2003, Rec. 2987/1995.

STS, Sala Tercera, de lo Contencioso-administrativo, Sección 7. a de 27 de abril de 2005, Rec. 4391/1999.

STS, Sala Tercera, de lo Contencioso-administrativo, Sección 7. ${ }^{\text {, de }} 28$ de marzo de 2001, Rec. 8749/1996, FJ 4, y de 14 de julio de 2005, Rec. 6820/1999

STS, Sala Tercera, de lo Contencioso-administrativo, Sección 7. a , de 20 de mayo de 1993.

STSJ de Andalucía de Granada, Sala de lo Contencioso-administrativo, Sección 3. ${ }^{a}$, de 14 de noviembre de 2018, Rec. $897 / 2018$.

STSJ de Andalucía de Granada, Sala de lo Contencioso-administrativo Sección 3. ${ }^{\text {a }}$, de 17 de noviembre de 2014, Rec. $1574 / 2010$

STSJ de Andalucía de Sevilla, Sala de lo Contencioso-administrativo, Sección 1. a , de 29 de abril de 2019 , Rec. $62 / 2019$

STSJ de Andalucía de Sevilla, Sala de lo Contencioso-administrativo, Sección 2. a de 9 de marzo de 2017, Rec. $798 / 2014$.

STSJ de Aragón, Sala de lo Contencioso-administrativo, Sección 3. ${ }^{a}$, de 5 de diciembre de 2016.

STSJ de Aragón, Sala de lo Contencioso-administrativo, Sección 3. ${ }^{a}$, de 27 de marzo de 2014, Rec. 333/2010.

STSJ de Aragón, Sala de lo Contencioso-administrativo, Sección 2. ${ }^{a}$, de 27 de marzo de 2002, Rec. 104/2001.

STSJ de Castilla y León de Valladolid, Sala de lo Contencioso-administrativo, Sección 1. a , de 29 de mayo de 2019 , Rec. 67/2019. 
STSJ de Cataluña, Sala de lo Contencioso-administrativo, Sección 4. ${ }^{\text {a }}$, de 20 de junio de 2019, Rec. 330/2017.

STSJ de Cataluña, Sala de lo Contencioso-administrativo, Sección 4. ${ }^{a}$, de 5 de junio de 2015, Rec. 20/2015.

STSJ de Cataluña, Sala de lo Contencioso-administrativo, Sección 4. ${ }^{a}$, de 5 de julio de 2012, Rec. $210 / 2011$.

STSJ de Galicia, Sala de lo Contencioso-administrativo, Sección 1. ${ }^{a}$, de 26 de abril de 2017, Rec. 446/2016.

STSJ de Galicia, Sala de lo Social, de 30 de mayo de 2014, Rec. 4013/2012.

STSJ de Galicia, Sala de lo Social, de 31 de enero de 2014, Rec. 6079/2011.

STSJ de Galicia, Sala de lo Social, de 19 de marzo de 2013, Rec. 561/2010.

STSJ de la Comunidad Valenciana, Sala de lo Contencioso-administrativo, Sección 2. a de 3 de mayo de 2017, Rec. $452 / 2014$.

STSJ de la Comunidad Valenciana, Sala de lo Contencioso-administrativo, Sección 2. ${ }^{a}$ de 30 de octubre de 2013, Rec. $676 / 2011$.

STSJ de la Región de Murcia, Sala de lo Contencioso-administrativo, de 23 de marzo de 2016, Rec. 286/2015.

STSJ de Madrid, Sala de lo Contencioso-administrativo, Sección 7. a, de 22 de enero de 2018, Rec. 85/2017.

STSJ de Madrid, Sala de lo Contencioso-administrativo, Sección 7. ${ }^{a}$, de 23 de noviembre de 2015, Rec. $181 / 2014$.

STSJ de Madrid, Sala de lo Contencioso-administrativo, Sección 7. a, de 3 de marzo de 2014, Rec. 514/2012.

STSJ de Madrid, Sala de lo Social, Sección 4. a , de 24 de abril de 2001, Rec. 1239/2001.

STSJ del País Vasco, Sala de lo Contencioso-administrativo, Sección 3. a, de 31 de diciembre de 2003, Rec. $412 / 2003$.

STSJ del País Vasco, Sala de lo Contencioso-administrativo, Sección 1. a , de 2 de julio de 2001, Rec. 40/2001.

STSJ del Principado de Asturias, Sala de lo Contencioso-administrativo, Sección 1. a de 18 de marzo de 2019, Rec. 907/2017.

STSJ del Principado de Asturias, Sala de lo Contencioso-administrativo, Sección 1. ${ }^{\text {, }}$, de 22 de mayo de 2017 , Rec. $79 / 2017$

SJCA núm. 3 de Pontevedra, de 19 de septiembre de 2016, P. A. 135/2016.

Providencia de la Sección $1 .^{a}$ de la Sala de lo Contencioso-administrativo del TS, de 25 de enero de 2018, Rec. núm. $4658 / 2017$

\section{ANEXO NORMATIVO}

Real Decreto de 24 de julio de 1889, texto de la edición del Código Civil mandada publicar en cumplimiento de la Ley de 26 de mayo último.

Constitución española, de 27 de diciembre de 1978.

Decreto de 30 de mayo de 1952 por el que se aprueba el texto del Reglamento de funcionarios de la Administración local.

Ley de Procedimiento Administrativo de 17 de julio de 1958.

Ley 22/1993, de 29 de diciembre, de medidas fiscales, de reforma del régimen jurídico de la función pública y de la protección por desempleo.

Ley 30/1984, de 2 de agosto, de Medidas para la reforma de la Función Pública.

Ley $7 / 1985$, de 2 de abril, reguladora de las Bases del Régimen Local.

Ley Orgánica 6/1985, de 1 de julio, del Poder Judicial.

Ley 6/1985, de 28 de noviembre, de Ordenación de la Función Pública de la Junta de Andalucía.

Ley 3/1985, de 26 de diciembre, de Ordenación de la Función Pública de la Administración del Principado de Asturias.

Ley 1/1986, de 10 de abril, de la Función Pública de la Comunidad de Madrid.

Real Decreto Legislativo 781/1986, de 18 de abril, por el que se aprueba el texto refundido de las disposiciones legales vigentes en materia de régimen local.

Real Decreto 2003/1986, de 19 de septiembre, por el que se aprueba el Reglamento Orgánico de los Cuerpos de Oficiales, Auxiliares y Agentes de la Administración de Justicia.

Ley 2/1987, de 30 de marzo, de la Función Pública Canaria.

Ley 6/1989, de 6 de julio, de la Función Pública Vasca.

Ley 3/1990, de 29 de junio, de Función Pública de la Administración Pública de la Comunidad Autónoma de la Rioja.

Decreto Legislativo 1/1990, de 26 de julio, por el que se aprueba el Texto Refundido de la Ley de la Función Pública de Extremadura.

Decreto Legislativo 1/1991, de 19 de febrero, por el que se aprueba el Texto Refundido de la Ley de Ordenación de la Función Pública de la Comunidad Autónoma de Aragón.

Ley 3/1990, de 29 de junio, de Función Pública de la Administración Pública de la Comunidad Autónoma de la Rioja.

Decreto 214/1990, de 30 de junio, por el que se aprueba el Reglamento del personal al servicio de las entidades locales de Cataluña.

Decreto Legislativo 1/1991, de 19 de febrero, por el que se aprueba el Texto Refundido de la Ley de Ordenación de la Función Pública de la Comunidad Autónoma de Aragón.

Decreto 92/1991, de 10 de marzo, por el que se aprueba el Reglamento de situaciones administrativas de los funcionarios de la Administración de la Comunidad Autónoma de Galicia. 
Ley 30/1992, de 26 de noviembre, de Régimen Jurídico de las Administraciones Públicas y del Procedimiento Administrativo Común.

Ley 4/1993, de 10 de marzo, reguladora de la Función Pública de la Administración de la Diputación Regional de Cantabria.

Decreto Foral Legislativo 251/1993, de 30 de agosto, del Texto Refundido del Estatuto del Personal al Servicio de las Administraciones Públicas de Navarra.

Ley 22/1993, de 29 de diciembre, de medidas fiscales, de reforma del régimen jurídico de la función pública y de la protección por desempleo.

Real Decreto 1777/1994, de 5 de agosto, de adecuación de las normas reguladoras de los procedimientos de gestión de personal.

Real Decreto 364/1995, de 10 de marzo, por el que se aprueba el Reglamento General de Ingreso del Personal al servicio de la Administración general del Estado y de Provisión de Puestos de Trabajo y Promoción Profesional de los Funcionarios Civiles de la Administración general del Estado.

Real Decreto 365/1995, de 10 de marzo, por el que se aprueba el Reglamento de situaciones administrativas de los funcionarios civiles de la Administración General del Estado.

Real Decreto 249/1996, de 16 de febrero, por el que se aprobaron sucesivos reglamentos orgánicos de los cuerpos de oficiales, auxiliares y agentes al servicio de la Administración de Justicia.

Ley 13/1996, 30 diciembre, de Medidas Fiscales, Administrativas y del Orden Social.

Decreto Legislativo 1/1997, de 31 de octubre, por el que se aprueba la refundición en un texto único de los preceptos de determinados textos legales vigentes en Cataluña en materia de función pública.

Ley 50/1997, de 27 de noviembre, del Gobierno.

Decreto Legislativo 2/2003, de 28 de abril, por el que se aprueba el texto refundido de la Ley municipal y de régimen local de Cataluña.

Ley Orgánica 19/2003, de 23 de diciembre, de modificación de la Ley Orgánica 6/1985, de 1 de julio, del Poder Judicial. Ley $7 / 2005$, de 24 de mayo, de la Función Pública de Castilla y León.

Ley $3 / 2007$, de 27 de marzo, de la Función Pública de la comunidad autónoma de las Islas Baleares.

Real Decreto 1083/2009, de 3 de julio, Memoria del análisis de impacto normativo.

Ley 10/2010, de 9 de julio, de la Generalitat, de Ordenación y Gestión de la Función Pública Valenciana.

Ley 16/2010, de 17 de diciembre, organización y funcionamiento Administración general y sector público autonómico de Galicia.

Ley 4/2011, de 10 de marzo, del Empleo Público de Castilla-La Mancha.

Ley $2 / 2015$, de 29 de abril, del Empleo Público de Galicia.

Ley 13/2015, de 8 de abril, de Función Pública de Extremadura.

Ley 39/2015, de 1 de octubre, del Procedimiento Administrativo Común de las Administraciones Públicas.

Ley 40/2015, de 1 de octubre, de Régimen Jurídico del Sector Público.

Real Decreto Legislativo 8/2015, de 30 de octubre, por el que se aprueba el texto refundido de la Ley General de la Seguridad Social.

Real Decreto Legislativo 5/2015, de 30 de octubre, por el que se aprueba el texto refundido de la Ley del Estatuto Básico del Empleado Público.

Real Decreto 128/2018, de 16 de marzo, por el que se regula el régimen jurídico de los funcionarios de Administración local con habilitación de carácter nacional. 